\title{
Transition age youth mental health: addressing the gap with telemedicine
}

\author{
Susheel K. Khetarpal ${ }^{1 *+}\left(\mathbb{0}\right.$, Lauren S. Auster ${ }^{2 \dagger}$, Elizabeth Miller ${ }^{1,3}$ and Tina R. Goldstein ${ }^{1,4}$
}

\begin{abstract}
Transition age youth (TAY), a demographic spanning ages 15-26, navigate a myriad of developmental transitions, ranging from identity formation and intimate relationships to substance use. Unfortunately, many young adults continue to have a dearth of mental health services and programing tailored to their unique developmental needs. Moreover, the systems of care in place are generally designed for treating traditional pediatric and adult patients but not ideally suited to meet the needs of TAY. Given the additional stressors from the COVID-19 pandemic, TAY are now, more than ever, in need of routine mental health care. We posit that the rapid expansion of telemedicine programming developed in response to the pandemic could be beneficial in mitigating this historic gap in care. In this commentary, we call on mental health providers and researchers to expand and invest in the growing number of telemedicine interventions and programming for this population so that TAY can begin to receive the care they so desperately need.
\end{abstract}

Keywords: Adolescent, Transition age youth, COVID-19, Telemedicine, E-therapy, Transition to adult services, Health care policy, Health care access

\section{Introduction}

Transition age youth (TAY) encompasses a broad demographic spanning from older adolescence to young adulthood (15-26 years old). This population includes diverse subgroups of youth, who vary across broad domains, including but not limited to physical and behavioral health diagnoses, education, socioeconomic status, and social determinants of health.

What unites all TAY, however, is that they experience a myriad of psychosocial transitions [1-3]. These include gaining and maintaining independence, identity formation, exploring sexuality and relationships, post-secondary education, career development, and engaging in behaviors that have potential for poor health outcomes

\footnotetext{
*Correspondence: skk30@pitt.edu

†'SusheelK. Khetarpal and Lauren S. Auster contributed equally to this work

1 University of Pittsburgh School of Medicine, 3550 Terrace Street, Pittsburgh, PA 15213, USA

Full list of author information is available at the end of the article
}

(e.g., substance use, violence, self-harm) [1, 2]. This developmental stage also appears particularly vulnerable to new-onset of mental health disorders, including mood, psychotic, and substance use disorders as well as suicide ideation and attempts [1-3]. Moreover, the mental health needs of TAY have escalated during the COVID-19 pandemic, with social distancing policies disrupting daily routines, social supports, relationships, employment, and typical coping strategies including connections with friends [4-7].

Despite this ever-clear need for behavioral health care, TAY experience numerous unique barriers to receiving mental health resources, including rigid cutoffs for pediatric services ending between ages 18-21, lack of systematic transition from school-based services after graduation from high school, unfamiliarity with adult mental health providers and resources, difficulty navigating transitions from pediatric to adult systems of care, and greater perceived responsibility and ownership for medical decisions [1-3]. These obstacles reinforce the already low rates of mental health care seeking as well as 
treatment receipt and retention among TAY, maintaining the gap in mental health care for this population [1-3]. Unfortunately, inadequate quantity and access to mental health resources during this critical developmental period can impact long-term trajectories of functioning [1]. By supporting young people with resources they need to navigate this transition to adulthood, we can mitigate against adverse health outcomes and, in turn, promote personal achievement and thriving.

Recognizing the unique needs of TAY nearly a decade ago, Wilens and Rosenbaum concluded in their clinical perspective piece titled Transitional Aged Youth: A New Frontier in Child and Adolescent Psychiatry that "child and adolescent psychiatrists are uniquely situated for the direct clinical care of TAY and to oversee the care of TAY in innovative programs" [3].

Despite these recommendations, there remains a dearth of mental health programs designed for TAY across a variety of medical disciplines (i.e., family medicine, pediatrics, adult medicine, and child psychiatry). Those documented in the literature, while demonstrating feasibility, primarily focus on subgroups within the broader TAY population (e.g., TAY with Autism Spectrum Disorder) [8] and often rely on school- and collegebased care structures $[8,9]$, which are not applicable to all TAY. Furthermore, racial, ethnic, and geographic disparities in TAY mental healthcare access and outcomes remain, with minoritized youth often not receiving care [1-3]. For example, even though adolescents living in neighborhoods with concentrated disadvantage often receive mental health supports in public grade schools, this source of services and supports drops off dramatically when these youth graduate high school, especially for those who move into the workforce directly rather than continuing with higher education[1-3]. Recognizing the structural inequities by race, gender, and access to healthcare among this population, coupled with the unique experiences and stressors of young adulthood, more inclusive and equitable mental health interventions are needed urgently.

With the onset of the COVID-19 pandemic, telemedicine has become more ubiquitous and may be one strategy for reaching TAY more broadly $[5,6]$, especially given this population's general comfort using social media and technology to connect, communicate, and create $[10,11]$. In response to the COVID-19 pandemic, health systems have expanded virtual and app-based services, including but not limited to hotlines, video-based therapy, peersupport groups, medical apps, and ecological momentary interventions $[6,10-12]$. Beyond accessibility, there is growing support that telehealth programs may provide equivalently effective care for adolescents across a variety of mental health conditions [11, 13]. For example,
KANOPEE, a free smart phone app developed in France to help youth with sleeping behaviors made worse in the context of COVID-19, is a feasible telehealth intervention for adolescents addressing topics relevant to their health and well-being [14]. Many other examples of COVIDrelevant telehealth programs for pediatric mental health exist and continue to be studied for their acceptability and effectiveness [15].

Within a social justice and health equity framework, telehealth could improve access to and receipt of care by reaching TAY with geographic barriers to care as well as those without access to institutions where care is typically delivered $[10,13]$. Programs could also be paired with a referral system to support youth requiring specialized treatment. For example, from a prevention perspective, implementing promising transdiagnostic interventions that target common stressors (e.g., sleep, interpersonal relationships, transition to independence) could assist a larger number of minoritized youth and connect them with mental health clinicians and resources for more specialized care as necessary [16].

Critical to the success of virtual mental healthcare for TAY will be identifying barriers to telemedicine and developing subsequent solutions. Notable barriers include limited patient privacy and confidentiality, lack of co-location within an interdisciplinary team, lack of appropriate technology among patients (especially those living in poverty), loss of connectedness between providers and patients, language barriers, and high attrition rates, to name a few $[17,18]$. While telehealth programming to date has largely not been able to rectify these shortcomings, many promising strategies warrant continued investigation. Proposed solutions to the abovementioned barriers include the creative use of video conferencing features, bolstering an internal referral system, individualizing sessions when possible, providing technical support or hybrid care formats, and integrating interpretation services into the telemedicine platform $[18,19]$. Such solutions could be similarly applied to virtual mental health programming for TAY.

Another growing challenge to rapid expansion of telemedicine for TAY mental health services in the United States is lack of reliable, adequate insurance coverage, and reimbursements [20]. The relaxation of this barrier in March 2020 for provision of clinical care during the COVID-19 pandemic allowed behavioral health providers to reach their patients and provide continuity of care [20]. Now, numerous states are debating when this emergency provision will end, and a standardized approach for how to cover the ongoing, tremendous demand for telehealth has not yet emerged at the federal level. We advocate for continuing reimbursement for and reducing restrictions on telemedicine services, as patients 
continue to seek mental health care in the ongoing aftermath of COVID-19.

\section{Conclusion statement}

Although Wilens and Rosenbaum coined transition aged youth (TAY) as the "new frontier" nearly a decade ago [3], TAY continue to lack adequate and developmentally appropriate access to mental health care. We posit the rapid expansion of telemedicine in the context of the COVID-19 pandemic provides mental health providers across numerous disciplines a unique opportunity to address this gap, work towards more equitable care, and better equip our young adults to prosper and thrive.

\section{Acknowledgements}

None to report.

\section{Authors' contributions}

All authors have participated in the concept, design, drafting or revising of the manuscript. All authors read and approved the final manuscript.

\section{Funding}

None to report (commentary article).

Availability of data and materials

Not Applicable (commentary article).

\section{Declarations}

Ethics approval and consent to participate

Not Applicable (commentary article).

\section{Consent for publication}

None of the material submitted here has been published or is under consideration for publication elsewhere. The authors confirm that the manuscript is only being submitted to $C A P H$, that it will not be submitted elsewhere while under consideration, and, that should it be accepted, we consent for this manuscript to be published in $\mathrm{CAPH}$.

\section{Competing interests}

The authors have no potential, real or perceived conflicts of interest to report.

\section{Author details}

${ }^{1}$ University of Pittsburgh School of Medicine, 3550 Terrace Street, Pittsburgh, PA 15213, USA. ${ }^{2}$ Department of Psychiatry, University of California San Francisco, San Francisco, CA, USA. ${ }^{3}$ Division of Adolescent and Young Adult Medicine, UPMC Children's Hospital of Pittsburgh, Pittsburgh, PA, USA. ${ }^{4}$ Department of Psychiatry, Western Psychiatric Hospital, Pittsburgh, PA, USA.

Received: 16 October 2021 Accepted: 24 January 2022

Published online: 02 February 2022

\section{References}

1. National Research Council. Investing in the health and well-being of young adults. Washington, DC: The National Academies Press; 2015. https://doi.org/10.17226/18869.

2. Martel A, Fuchs DC. Transitional age youth and mental illness: influences on young adult outcomes. Child Adolesc Psychiatr Clinics N Am. 2017;26(2):I. https://doi.org/10.1016/s1056-4993(17)30004-4.

3. Wilens TE, Rosenbaum JF. Transitional aged youth: a new frontier in child and adolescent psychiatry. J Am Acad Child Adolesc Psychiatr. 2013;52(9):887-90.
4. "Adolescent's wellbeing during COVID-19: Parental Resources", National Center for Immunization and Respiratory Diseases - Centers for Disease Control and Prevention. 2021. https://www.cdc.gov/coronavirus/ 2019-ncov/daily-life-coping/parental-resourcekit/adolescence.html. Accessed 3 Apr 2021.

5. Di Carlo F, Sociali A, Picutti E, Pettorruso M, Vellante F, Verrastro V, Martinotti G, di Giannantonio M. Telepsychiatry and other cutting-edge technologies in COVID-19 pandemic: bridging the distance in mental health assistance. Int J Clin Pract. 2021;75(1):e13716. https://doi.org/10. 1111/ijcp.13716.

6. Torous J, Wykes T. Opportunities from the coronavirus disease 2019 pandemic for transforming psychiatric care with telehealth. JAMA Psychiatry. 2020;77(12):1205-6. https://doi.org/10.1001/jamapsychiatry. 2020.1640.

7. Ragavan MI, Culyba AJ, Muhammad FL, Miller E. Supporting adolescents and young adults exposed to or experiencing violence during the COVID-19 pandemic. J Adolesc Health. 2020;67(1):18-20. https:// doi.org/10.1016/j.jadohealth.2020.04.011 Epub 2020 Apr 23.

8. White SW, Elias R, Capriola-Hall NN, Smith IC, Conner CM, Asselin SB, Howlin P, Getzel EE, Mazefsky CA. Development of a college transition and support program for students with autism spectrum disorder. J Autism Dev Disord. 2017:47(10):3072-8. https://doi.org/10.1007/ s10803-017-3236-8.

9. Chugani CD, Goldstein TR, Salk RH, Poling K, Sakolsky D, Brent D. Group intervention for young adults with mood and anxiety disorders transitioning to college. J Psychiatr Pract. 2020;26(2):120-5. https://doi.org/ 10.1097/PRA.0000000000000456.

10. Domhardt M, Steubl L, Baumeister H. Internet- and mobile-based interventions for mental and somatic conditions in children and adolescents. Z Kinder Jugendpsychiatr Psychother. 2020;48(1):33-46. https:// doi.org/10.1024/14224917/a000625 Epub 2018 Nov 13.

11. Per CG, Andersson P, Cuijpers HR, Erik H-L. Internet-based vs face-toface cognitive behavior therapy for psychiatric and somatic disorders: an updated systematic review and meta-analysis. Cogn Behav Ther. 2018;47(1):1-18. https://doi.org/10.1080/16506073.2017.1401115.

12. O'Dea B, Han J, Batterham PJ, Achilles MR, Calear AL, Werner-Seidler A, Parker B, Shand F, Christensen H. A randomised controlled trial of a relationship-focussed mobile phone application for improving adolescents' mental health. J Child Psychol Psychiatry. 2020;61(8):899-913. https://doi.org/10.1111/jcpp.13294 Epub 2020 Jul 19.

13. Hilty DM, Ferrer DC, Parish MB, Johnston B, Callahan EJ, Yellowlees PM. The effectiveness of telemental health: a 2013 review. Telemed J E Health. 2013;19(6):444-54. https://doi.org/10.1089/tmj.2013.0075.

14. Philip P, Dupuy L, Morin CM, et al. Smartphone-based virtual agents to help individuals with sleep concerns during COVID-19 confinement: feasibility study. J Med Internet Res. 2020;22(12):e24268.

15. Cunningham NR, Ely SL, Barber Garcia BN, Bowden J. Addressing pediatric mental health using telehealth during coronavirus disease-2019 and beyond: a narrative review. Acad Pediatr. 2021;21(7):1108-17. https://doi.org/10.1016/j.acap.2021.06.002.

16. Jeppesen P, Wolf RT, Nielsen SM, et al. Effectiveness of transdiagnostic cognitive behavioral psychotherapy compared with management as usual for youth with common mental health problems: a randomized clinical trial. JAMA Psychiatry. 2021;78(3):250-60. https://doi.org/10. 1001/jamapsychiatry.2020.4045.

17. Barney A, Buckelew S, Mesheriakova V, Raymond-Flesch M. The COVID19 pandemic and rapid implementation of adolescent and young adult telemedicine: challenges and opportunities for innovation. J Adolesc Health. 2020;67(2):164-71. https://doi.org/10.1016/j.jadoh ealth.2020.05.006 Epub 2020 May 14

18. Fernández-Álvarez J, Díaz-García A, González-Robles A, Baños R, GarcíaPalacios A, Botella C. Dropping out of a transdiagnostic online intervention: a qualitative analysis of client's experiences. Internet Intervent. 2017;10:29-38. https://doi.org/10.1016/j.invent.2017.09.001.

19. Meyerowitz-Katz G, Ravi S, Arnolda L, Feng X, Maberly G, Astell-Burt T. Rates of attrition and dropout in app-based interventions for chronic disease: systematic review and meta-analysis. J Med Internet Res. 2020;22(9):e20283.

20. Wang RH, Barbieri JS, Nguyen HP, Stavert R, Forman HP, Bolognia JL, Kovarik CL, Group for Research of Policy Dynamics in Dermatology. Clinical effectiveness and cost-effectiveness of teledermatology: Where 
are we now, and what are the barriers to adoption? J Am Acad Dermatol. 2020;83(1):299-307 Epub 2020 Feb 5.

\section{Publisher's Note}

Springer Nature remains neutral with regard to jurisdictional claims in published maps and institutional affiliations.

Ready to submit your research? Choose BMC and benefit from:

- fast, convenient online submission

- thorough peer review by experienced researchers in your field

- rapid publication on acceptance

- support for research data, including large and complex data types

- gold Open Access which fosters wider collaboration and increased citations

- maximum visibility for your research: over 100M website views per year

At $\mathrm{BMC}$, research is always in progress.

Learn more biomedcentral.com/submissions 